\title{
Nucleic Acid-Based Strategies for the Treatment of Coxsackievirus-Induced Myocarditis
}

\author{
Decheng Yang \\ Department of Pathology and Laboratory Medicine, University of British Columbia, \\ The Institute for Heart and Lung Health, St. Paul's Hospital, Vancouver, B. C.,
}

Canada

\section{Introduction}

Viral myocarditis is the most common heart disease in infants, children, young adults and pregnant women. Although a number of viruses from different genera, such as adenovirus, hepatitis $\mathrm{C}$ virus (HCV), parvoviruses and cytomegalovirus have been reported to cause myocarditis (Bowles et al., 2003; Kindermann et al., 2008; Kuhl et al., 2005a; Kuhl et al., 2005b; Kyto et al., 2005; Mahrholdt et al., 2006; Matsumori, 2005; Matsumori et al., 2006), coxsackievirus, particularly coxsackievirus B3 (CVB3), is generally considered the primary etiological agent of myocarditis (Blauwet, 2010; Kuhl et al., 2005a; Mahrholdt et al., 2006). CVB3 infection of the heart is often persistent and enters the chronic phase, leading to dilated cardiomyopathy (DCM)(Andreoletti et al., 2009; L. T. Cooper, Jr., 2009; Kuhl et al., 2005b; Yajima\& Knowlton, 2009), a squelae of viral myocarditis characterized by ventricular chamber dilation, increased wall thickness, weaker beating and abnormal heart function. Patients with DCM eventually develop into congestive heart failure.

To date, there is no clinically proven specific treatment available for viral myocarditis and DCM. Patients with DCM eventually need heart transplantation as the final treatment (Schultz et al., 2009). The managements for viral myocarditis are usually supportive therapies, such as improvements in cardiophysiology with medicine used to treat other kinds of heart diseases, and application of non-specific antiviral agents to decrease the viral load. The former measurements include administration of angiotensin-converting enzyme inhibitor or angiotensin receptor blockade, beta-adrenergic blockade, diuretics, etc (Dennert et al., 2008; Rose, 2009; Schultz et al., 2009); the later measurements include application of type I interferons or nucleotide analogs such as ribavirin, which is reviewed elsewhere (Blauwet, 2010; Dennert\& Crijns\& Heymans, 2008; Schultz et al., 2009). If myocarditis was caused by an autoimmune disorder, it would be appropriately treated by immunosuppression (Rose, 2009; Schultz et al., 2009). However, the effectiveness of treatment with immunosuppressive therapies has not reached a consensus amongst different studies. This can probably be attributed to the difficulty of confirmation and diagnosis of the etiology and pathogenesis of myocarditis. Thus it is very important to distinguish infectious and autoimmune disease since the same methods of treatment will not be optimal for both forms of heart muscle diseases. The diagnostic gold standard is endomyocardial biopsies with the histological Dallas criteria, in association with new 
immunohistochemical and viral PCR analyses of cardiac tissues (L. T. Cooper et al., 2007). In case of confirmed autoimmune-related disease and lack of detectable viral infection, an immunosuppressive treatment combining corticoids and azathioprine may be beneficial to the patients (Frustaci et al., 2003). However, if the disease is primarily caused by viral infections, more specific antiviral agents would be the ideal drugs of choice. In recent years, the search for such antiviral drugs has become a new trend in drug development for treatment of viral myocarditis. The strategies for developing such antivirals include i) screening chemical compounds, such as Pleconaril, capable of interacting with picornavirus (particularly human rhinovirus) antireceptor to block viral entry of the host cells (Groarke\& Pevear, 1999; Kaiser et al., 2000; Reisdorph et al., 2003), ii) application of herb medicine to reduce viral load or boost immune responses to limit viral replication (Si et al., 2007; Y. F. Wang et al., 2009), iii) development of small peptide inhibitors of viral proteases to block CVB3 replication cycle (Maghsoudi et al., 2010) and iv) production of recombinant soluble protein of coxsackievirus-adenovirus receptor (CAR) fused to a human immunoglobulin (sCAR-Fc) to block coxsackievirus B3 entry (Pinkert et al., 2009; Werk et al., 2009; Yanagawa et al., 2003; Yanagawa et al., 2004). Another very attractive and promising trend in drug development is the nucleic acid (NA)-based approach to target viral genome or cellular genes to block viral translation and transcription. These strategies include design and synthesis of antisense oligonucleotide (ASON), ribozyme, short interfering RNA (siRNA) and artificial microRNA (miRNA). In this chapter we will focus our discussion on the recent state of this group of antiviral agents for the treatment of myocarditis caused by CVB3 and other viruses that have been recently reported as causal agents of myocarditis.

\section{CVB3 genome organization and its receptor}

CVB3, a member of enterovirus in the Picornaviridae family, is a positive single-stranded, non-enveloped RNA virus. Its genome is $\sim 7.4 \mathrm{~kb}$ long containing a single long open reading frame (encoding 11 proteins) flanking by the $5^{\prime}$ and $3^{\prime}$ untranslated regions (UTRs) (Klump et al., 1990). The 5'UTR is unusually long (741 nucleotides (nt)) and harbors a number of cisacting translational elements, such as internal ribosomal entry site (IRES) and cloverleaf sequence (Cheung et al., 2007; Z. Liu et al., 1999; Verma et al., 2010; Yang et al., 1997), which are crucial structures for viral translation and transcription. The $3^{\prime} \mathrm{UTR}$ is a 99-nt long segment attached with a poly-A tail. The 3'UTR folds to form kissing-loop tertiary structures, which are believed to play a role in facilitating viral transcription of the negative strand of CVB3 replication intermediate (Melchers et al., 1997; J. Wang et al., 1999). The viral genomic RNA can directly serve as a mRNA template for translation of a single long polyprotein, which is processed by viral proteases to produce eleven individual proteins, among which four are structural proteins, VP1-VP4, and seven are non-structural proteins including proteases, 2A and 3C, as well as a RNA-dependent RNA polymerase 3D. These three enzymatic proteins play important roles in viral life cycle and pathogenesis (Knowlton, 2008).

CVB3 is a cardiotropic virus. It infects cardiomyocytes by endocytosis through viral receptor CAR (coxsackie and adenovirus receptor) colocalized with tight junction protein (e.g., occludin) (Raschperger et al., 2006). Structural analysis of CAR D1 domain supports the proposed function of CAR as a mediator of cell adhesion (Honda et al., 2000) in the junction complexes of epithelial cells in many tissues (Cohen et al., 2001). It is also known that CAR binding site (anti-receptor) on CVB3 particle lies in the canyon on the capsid surface. Upon 
attachment of CVB3 particles to CAR, the receptor changes conformation to form the viral A-particle, a product of the interactions between CVB3 and CAR, which then allows for the release of viral RNA into host cells and begins viral translation and transcription. The observation that soluble CAR can function as a virus trap leading to inactive A-particles has been suggested as a strategy for CVB3 therapy (Pinkert et al., 2009; Werk et al., 2009; Yanagawa et al., 2004). Depending on the different combination of viral strains and mouse models in study of CVB3 infection, a CVB3 co-receptor called decay accelerating factor (DAF, CD55) is sometimes also necessary for CVB3 entry of the host cells (Freimuth et al., 2008; Shafren et al., 1997). Thus, genes encoding CAR and DAF are important candidates for study of viral tropism and rationale targets for antiviral drug design.

\section{NA-based antiviral strategies}

\subsection{Antisense oligonucleotide (ASON)}

ASON is probably the earliest NA-based antiviral agent developed. They are designed to bind a complementary sequence in the target mRNA to form RNA-DNA heteroduplexes. These double-stranded hybrid sequences are recognized by RNase $\mathrm{H}$, which digests the RNA strand in the duplex, releasing the ASON to bind another target and so on, effectively silencing the encoded gene (Walder \& Walder, 1988). Certain ASONs are not capable of activation of RNase $\mathrm{H}$; instead they inhibit gene translation by steric competition with the translational machinery. In addition, ASONs, if bound to pre-mRNA at intron-exon junctions, can disrupt mRNA splicing (Munroe, 1988). Furthermore, ASONs can also disrupt RNA trafficking by occupying protein-RNA interaction sequences necessary for correct intracellular localization. For example, hnRNP A2 response element (A2RE) is identified as a key sequence required for the trafficking of myelin basic protein (Shan et al., 2000).

Due to major problems including instability, non-specific delivery and unwanted side effects of the ASONs, the structure of this molecule has been modified extensively at different components (i.e., the bases, sugar or phosphate backbone) and has entered its third generation (Fig. 1). The first generation of chemical modification was designed to enhance nuclease resistance of ASON in serum (Stein et al., 1997). The representative of such is the phosphorothioate (PS) oligonucleotide $(\mathrm{ON})$, in which one of the non-bridging oxygen atoms in the phosphodiester bond is replaced by sulfur, intended to prevent cleavage by nucleases. Early antiviral PS-modified ASONs exhibited the antisense properties of phosphodiester ASONs, such as the ability to induce RNase $\mathrm{H}$ activation, while showing enhanced stability in vitro for up to 48 hours (Hoke et al., 1991); reviewed in (Kurreck, 2003). One notable property of PS-ASON is their tendency to form aptamers, i.e., nonspecific interactions with proteins due to its negative charge. This is disadvantageous intracellularly because aptamer interactions can impede ASON interaction with its intended target, and hence its function. Conversely, the tendency for PS-ASONs to bind serum proteins albumin and alpha-2 macroglobulin in circulation actually improves their bio-distribution throughout the body in vivo and prevents them from being cleared for excretion (Crooke et al., 1996).

Another strategy to increase the stability of ASONs is the addition of alkyl groups at the 2' position of the ribose. 2'-O-methyl (OMe) and 2'-O-methoxy-ethyl (MOE) substitutions sterically shield the backbone from nuclease access, and also increase affinity to the target, shown by increased $T_{m}$, thus stabilizing the duplex (Cotten et al., 1991). 2'-O-alkyl ASONs 
A

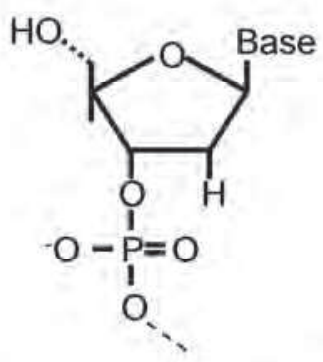

Unmodified (DNA)

C<smiles>[R]C1[C@H](OP(=O)([O-])OC)[C@@H]2O[C@@H]1O[C@H]2[13CH3]</smiles>

$\mathrm{R}: \mathrm{CH}_{3}$ or $\mathrm{O}-\mathrm{CH}_{3}$
B

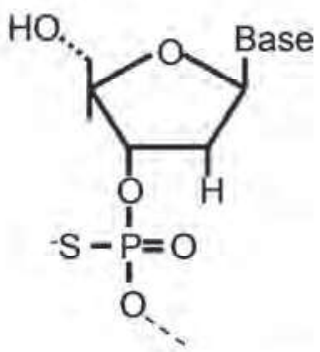

1st Generation

D<smiles>COP(=O)(OC)N1CC2CC(C1)OC(CO)N(C(=O)c1ccccc1)C2</smiles>

\section{2nd Generation}

\section{3rd Generation}

Fig. 1. Structures of certain nucleic acid analogs used to synthesize different generation ASONs. (A) unmodified deoxyribonucleotide. (B) Phosphorothioate modification of the phosphodiester backbone replaces the non-bridging oxygen with a sulfur atom. (C) Second generation ASONs with a 2'-akyl or 2'-methoxy ethyl groups further stabilize the molecule. (D) Phosphorodiamidate morpholino oligos have a modified backbone and modified sugar ring and are electrically neutral.

are also less toxic than PS-ASONs (Cotten et al., 1991); however, the 2'-O-alkyl group simultaneously shields heteroduplexed ASON-RNA from RNase $\mathrm{H}$ and therefore cannot induce direct cleavage of the target RNA. These modified ASONs function mainly by blocking translation via steric hindrance of elongating ribosome. In order to retain the advantage of the RNAse $\mathrm{H}$ mechanism while still conferring some benefits of 2'-O-alkyl protection, chimeric oligos containing both 2' unmodified and 2'-modified DNAs, called gapmers, were conceived. Gapmers are typically end-modified, allowing a normal DNARNA heteroduplex to form mid-strand, although they may also consist of centre-modified 
ASON flanked by normal DNA, or more commonly, phosphorothioate-linked DNA so as to capitalize on the advantages of both types of modifications (Turner et al., 2006). Both designs also reduce the polyanionic side effects of the phosphorothioate modification (Monia et al., 1993). 2'-O-alkyl modified ASONs and mixed backbone gapmer ASONs represent a second generation of ASON.

Third generation ASONs are phosphorodiamidate morpholino oligonucleotides (PMOs). PMOs are nonionic DNA analogues originally proven in loss of function knockdown studies in developmental systems such as zebrafish. The success and limitations of their usage have been recently reviewed comprehensively (Amantana\& Iversen, 2005; Heasman, 2002). PMOs have an altered structure in which the ribose is replaced by a morpholine moiety and phosphorodiamidate $\left(\mathrm{O}-\mathrm{PONH}_{2}-\mathrm{O}\right)$ linkers are used instead of phosphodiester bonds. Thus PMOs are resistant to digestion by nucleases and are electrically neutral, a property that reduces nonspecific interactions with intracellular proteins. Morpholinos form base pairs with target sequences, but the binding ability is no greater than binding of analogous DNA and RNA oligomers, necessitating the use of relatively long 25-base oligomers for antisense inhibition. In addition, PMO-RNA hybrids do not activate RNase H. Therefore, the mechanism by which the PMOs inhibit protein synthesis is via binding the critical mRNA elements, such as the mRNA 5'UTR or the start codon region, to prevent ribosomes from binding or scanning. Alternatively, PMOs may occupy the mRNA splice recognition site to block the normal posttranscriptional processing required for synthesis of the functional protein. A good example is the report on therapeutic application of PMOs to correct aberrant splicing of mutated $\beta$-globin precursor mRNA (Lacerra et al., 2000).

The limitations of PMOs are their low cellular uptake levels as compared to unmodified ASONs. To address this shortcoming, PMOs can be conjugated to certain positive peptide carriers such as arginine-rich HIV-TAT and drosophila antennapedia sequences (Cardarelli et al., 2007). Because PMOs have a standard phosphodiester linkage and are uncharged, the addition of a positive peptide conjugate does not cause the same aptamer interaction as that caused by PS-ASON, which contains negative oxygen atoms.

\subsection{Ribozymes}

Ribozymes are catalytically active small RNA ( 30-100 nts) molecules that act as enzymes to specifically cleave single strand RNA without the need of proteins. A major therapeutic advantage of ribozymes is the ability to make them trans-acting and to confer specificity to virtually cleave any target sequence (Peracchi, 2004). This can be achieved by fusing the ribozyme core sequence at the $5^{\prime}$ and $3^{\prime}$ ends with the sequences that are complementary to the target sequence. Of the nine groups of ribozymes, the hammerhead and hairpin ribozymes have received a great deal of attention (Scherer\& Rossi, 2003). Hammerhead ribozymes, originally identified from plant viroid and viroid RNA, are composed of about $30 \mathrm{nts}$ and have minimal requirements for the cleavage site, in which virtually any motif with the dinucleotide sequence UU, UC or UA can be targeted (Haseloff\& Gerlach, 1992). For this reason, hammerhead ribozyme is very popular for the design of therapeutic ribozymes. On the other hand, the hairpin ribozyme has a more complex structure and requirements for target sequences, with a preference for GUC and cleavage occurring directly upstream of the $\mathrm{G}$ residue (Kore et al., 1998).

An advantage of ribozyme over ASON is its catalytic mode of action, which should in principle require a much lower concentration of ribozymes as compared to non-catalytic 
ASONs. In addition, chemical modifications of ribozyme can increase its stability and improve therapeutic potential (Gonzalez-Carmona et al., 2006; Jakobsen et al., 2007). Antiviral ribozymes have been extensively tested in different gene therapy settings (Haasnoot et al., 2007). On the other hand, ribozyme also has its limitation, which is that target site selections are limited due to sequence requirements at the cleavage site and to structural constrains that interfere with ribozyme function to a higher extent (Frese, 2006). Therefore, the selection of appropriate target sites is of utmost importance which can not be predicted but must rather be determined empirically and which depends on the particular ribozyme used.

\subsection{RNAi-based strategies}

The term of RNA interference (RNAi) refers to a cellular process by which a double-strand RNA (dsRNA) sequence specifically inhibits the expression of a gene. This very efficient process of posttranscriptional gene silencing (PTGS) was discovered first in plant (Napoli et al., 1990) and served as a protection against viruses and genetic instability arising from transposons (Bartel, 2004). Accumulated evidence suggests that RNAi also plays a role in the antiviral defense mechanism in mammalian cells (Bennasser et al., 2005; Berkhout\& Jeang, 2007; Cullen, 2006; Lecellier et al., 2005). These findings fuel the interests of the researchers to use RNAi not only for study of gene regulation but also for antiviral drug development (Lecellier et al., 2005; Otsuka et al., 2007).

The specificity of RNA silencing is mediated by small RNAs called short interfering RNAs (siRNA) and microRNA (miRNA). Both types of RNAs are generated by members of the Dicer family. This group of class III endoribonucleases cleaves double stranded non-coding RNA into fragments with a length of 21-25 nts. For siRNA, the long dsRNA or transgeneexpressed short hairpin RNA (shRNA) is cleaved by Dicer. These RNAs are assembled into a multi-component complex, known as the RNA-induced silencing complex (RISC), which incorporates a single strand (antisense strand) of the siRNA serving as a guide sequence to silence the target gene (Hannon, 2002; Tomari\& Zamore, 2005) (Fig. 2). For miRNA, this endogenous gene regulator is processed from primary RNA (priRNA) transcripts of noncoding regions or introns of protein-coding polymerase II transcripts. They are processed by RNase III Drosha to approximately 70-nt long pre-miRNAs, which are transported into cytoplasm by exportin- 5 and are cleaved by Dicer to become the functional miRNA. Similar to siRNA, they also form a RISC with Argonaut proteins (having RNse H activity) and bind to their target mRNAs. The modes of actions of siRNA and miRNA depend on the degree of complementation between the siRNA or miRNA and their target sequences. siRNAs usually target coding regions by complementary base-paring and induce sequence-specific cleavage of mRNA substrate (Caudy et al., 2003); however, miRNA preferentially recognize target sequences in the 3'UTR of mRNAs and this target site is often in multi-copy (Brennecke et al., 2005; Grimson et al., 2007; Krek et al., 2005; Lewis et al., 2003). The binding of the miRNA often takes place with an incomplete homology, although a perfect base-pairing in the seed region (positions nt 2-8 from $5^{\prime}$ end of the antisense strand) of miRNA forms the core of interaction. Depending on the complete or partial homology between the miRNA and mRNA, the result can be cleavage of the target mRNA or repression of translation (Fig. 2) (Doench et al., 2003; Parker et al., 2005).

The precise mechanisms of RNAi-mediated suppression of gene expression have been studied extensively and made significant progress. The proposed mechanisms include the translation suppression by blocking the binding and scanning of ribosome and other 


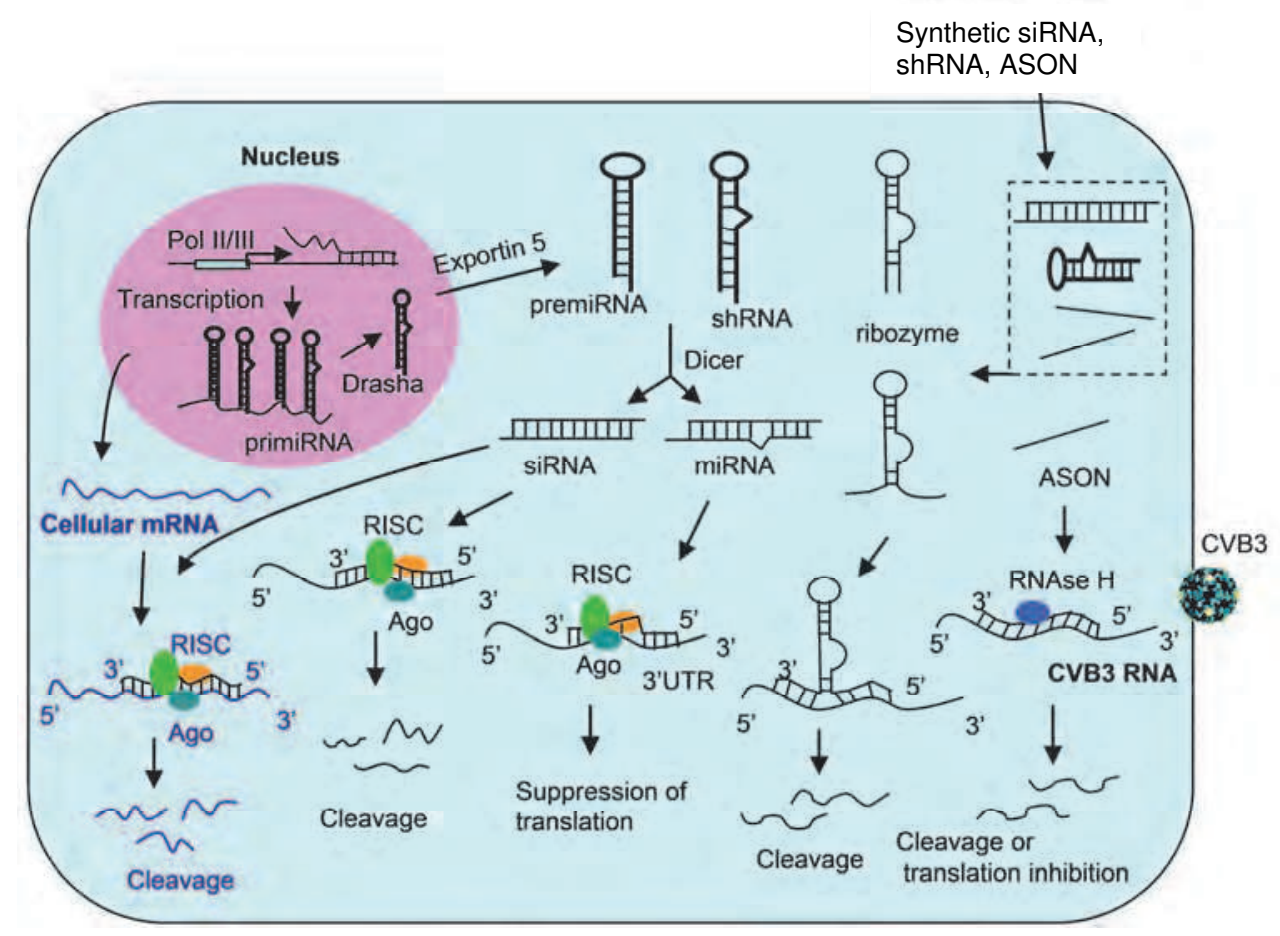

Fig. 2. NA-based antiviral strategies for pathogens of viral myocarditis. Antiviral nucleic acids can either be transfected into cells or expressed intracellularly. ASONs hybridize to viral mRNA to induce RNase H-mediated cleavage of RNA strand of the DNA-RNA duplexes. Some modified ASONs cannot induce RNase H but they have a high affinity for the target and inhibit translation by steric hindrance of ribosome or splicing. Binding of ribozymes to the target sequence can trigger cleavage of the viral RNA. siRNAs incorporated in the RISC target the viral RNA by perfect sequence complementation and induce cleavage of the target sequence by RNAse $\mathrm{H}$ activity of Ago protein. miRNAs (or AmiRNAs) target viral RNA by imperfect sequence complementation and induce gene silencing by destabilizing mRNAs (e.g., 3' deadenylation or 5' de-capping) and suppression of translation initiation and elongation. In addition, siRNAs can also target cellular genes (e.g., CAR and signal molecules) involved in viral entry and replication.

initiation factors on the mRNA or by disassociation of the premature translation initiation complexes. According to an alternative model, the mRNA destabilization is via miRNAinduced $3^{\prime}$ end de-adenylation or $5^{\prime}$ end de-capping, which results in degradation of mRNA after cleavage. Recently, some other mechanisms have been suggested. As review of the detailed mechanisms of RNAi action is beyond the scope of this article, the readers can refer to the recent reviews (Bartel, 2009; Carthew\& Sontheimer, 2009; Q. Liu, Paroo, Z., 2010; Moazed, 2009). It should be pointed out that RNAi strategies for antiviral design have some advantages over the ASONs. Although they all cleave target mRNAs by RNase $\mathrm{H}$, the modified ASON DNA induces activation of RNase $\mathrm{H}$ and cleavage of target sequence in nucleus, while the dsRNA functions primarily in cytoplasm. Ago2, the most important 
component of the RISC, is located in the p-bodies (Sen \& Blau, 2005). Its cytoplasm localization is critically important for anti-coxsackievirus action as this virus is replicated only in cytoplasm. In addition, in the case of RNAi, an endogenous cellular pathway is followed, which could explain the high efficiency with which siRNAs are able to reach 1000 times higher than the ASON in cleavage of the same target molecule (Bertrand et al., 2002; Grunweller et al., 2003). However, the limitations for RNAi are present (Hemida et al., 2010); similar to the ribozymes, the selection of the suitable target for binding is restricted, particularly for miRNA, as the search for effective targeting sites are often limited in the 3'UTR of mRNA.

\section{NA-based antivirals against CVB3 infection}

\subsection{Anti-CVB3 ASONs}

CVB3, one of the most frequently used model systems for study of viral replication and pathogenesis, is also widely employed for evaluation of NA-based antiviral agents. The early investigations mainly focused on the application of the second and third generations of the ASONs. McManus and coworkers are one of the pioneer groups to study the potential possibility to inhibit CVB3 replication using ASONs. Their earliest work using regular ASONs to target the different sites of 5'UTR of CVB3 genome successfully mapped the IRES by in vitro translation inhibition assay (Yang et al., 1997). This study provided useful information for the design of ASON for inhibiting CVB3 replication in vitro and in mouse models. Later, they used PS-ASONs targeting the $5^{\prime}$ and $3^{\prime}$ UTRs as well as the start codon region and found that the oligomers targeting the $5^{\prime}$ and $3^{\prime}$ proximate ends of the CVB3 genome are the most effective candidates to inhibit viral replication in HeLa cells. Each of these two ASONs resulted in $\sim 80 \%$ reduction of viral particle production, which is followed by the candidates targeting the IRES and the initiation codon region (A. Wang et al., 2001). The importance of these sites for ASON binding was further confirmed by in vivo evaluation using a murine myocarditis model, although the antiviral efficiency is not as high as that obtained from in vitro evaluation (Yuan et al., 2004).

To improve the stability of the oligomers, our group designed eight phosphorodiamidate morpholino oligomers (PMO) targeting both the sense and antisense strands of the CVB3 replication intermediate. To increase the efficiency of drug internalization, the PMO were conjugated to a cell-penetrating arginine-rich peptide. These modified ASONs were evaluated in HeLa cells and HL-1 cardiomyocytes in culture and in a murine myocarditis model (Yuan et al., 2006). One of the oligomers, designed to target a sequence in the $3^{\prime}$ portion of the CVB3 IRES, was found to be especially potent against CVB3. Treatment of cells with this oligomer prior to CVB3 infection produced an approximately 3- $\log _{10}$ decrease in viral titer and largely protected cells from a virus-induced cytopathic effect. A similar antiviral effect was observed when this oligomer treatment began shortly after the virus infection period. A/J mice receiving intravenous administration of this oligomer once prior to and once after CVB3 infection showed an $\sim 2-\log _{10}$-decreased viral titer in the myocardium at 7 days post infection and a significantly decreased level of cardiac tissue damage, compared to the controls (Yuan et al., 2006).

In addition to the many ASON reports, another strategy using CpG containing oligodeoxynucleotide to activate antiviral immunity has been reported (Cong et al., 2007). The mechanism is that the C-type of CpG oligomer can induce anti-CVB3 activity in human peripheral blood mononuclear cells (PBMCs) through the induction of synthesis of natural mixed interferons. 


\subsection{Antiviral ribozymes}

Ribozyme as an antiviral agent has been tested for many virus infections; however, report on anti-CVB3 has not been documented. Here, we will take HCV as an example to briefly discuss the potential application of ribozyme for the treatment of HCV infection, as many recent reports found that $\mathrm{HCV}$ is a new causal agent of myocarditis (Matsumori, 2005; Matsumori et al., 2006). To investigate the potential application of synthetic, stabilized ribozymes for the treatment of chronic HCV infection, Macejak et al. designed and synthesized hammerhead ribozymes targeting 15 conserved sites in the 5'UTR of HCV RNA including the IRES (Macejak et al., 2000). It was shown that the inhibitory activity of ribozyme targeting site at nucleotide 195 of HCV RNA exhibited a sequence-specific dose response, required an active catalytic ribozyme core, and was dependent on the presence of the HCV 5'UTR. In an investigation of new genetic approaches on the management of this infection, six hammerhead ribozymes directed against a conserved region of the plus strand and minus strand of the $\mathrm{HCV}$ genome were isolated from a ribozyme library that was expressed using recombinant adenovirus vectors (Macejak et al., 2001). Treatment with synthetic stabilized anti-HCV ribozymes and vector-expressed HCV ribozymes has the potential to aid in treatment of patients who are infected with HCV by reducing the viral burden through specific targeting and cleavage of the viral genome. Gonzalez-Carmona and colleagues used RNA transcripts from a construct encoding a HCV-5'-NCR-luciferase fusion protein to test four chemically modified HCV specific ribozymes in a cell-free system and in HepG2 or CCL13 cell lines. They found that ribozyme (Rz1293) showed an inhibitory activity of translation of more than $70 \%$ thus verifying that the GCA 348 cleavage site in the $\mathrm{HCV}$ loop IV is an accessible target site in cell culture and may be suitable for the development of novel optimized hammerhead structures (Gonzalez-Carmona et al., 2006).

\subsection{Anti-CVB3 siRNAs}

RNAi-mediated antiviral strategies can achieve much higher efficiency than ASONs. Thus, recent studies have focused on the design and evaluation of anti-CVB3 siRNAs. This group of small double-stranded RNAs, as a silencer of target gene expression, can virtually inhibit any genes of virus and cell if the site of targeting within the gene is unique. Thus, the target search for anti-CVB3 siRNAs is not only concentrating on CVB3 genome but also extending to the host cellular genes required for viral infection or replication.

\subsubsection{Targeting the CVB3 genome}

CVB3 genome harbors many cis-acting sequence elements for viral transcription and translation, such as the $5^{\prime}$ and $3^{\prime}$ UTRs, the IRES and other segments for binding of transcription and translation initiation factors. In addition, the viral genome also encodes many essential enzymes for CVB3 multiplication, such as proteases $2 \mathrm{~A}$ and $3 \mathrm{C}$ as well as the RNA-dependent RNA polymerase 3D. These structures are rationale targets for design of anti-CVB3 siRNAs. This hypothesis has been tested by a number of groups. The earlier selection of the siRNA targets was focused on CVB3 protease 2A. Almost at the same time, two groups independently found that inhibition of 2A protease by specific siRNAs significantly reduced CVB3 replication. The first group by Yuan et al., evaluated five siRNAs targeting the 5'UTR, AUG start codon, VP1, 2A and 3D, respectively and found that siRNA targeting 2A (nts 3543-3561) showed strongest anti-CVB3 activity in HeLa cells, resulting in $92 \%$ reduction of viral replication and siRNAs targeting VP1, 3D and the 5'UTR 
showed modest antiviral effects, respectively. By mutational analysis of the mechanism of siRNA action, they found that siRNA functions by targeting the positive strand of the virus and requires a perfect sequence match in the central region of the target, but mismatches were more tolerated near the $3^{\prime}$ end than the $5^{\prime}$ end of the antisense strand (Yuan et al., 2005). This finding on the targeting of siRNA to positive strand of CVB3 was further supported by a later study using siRNA targeting the CVB3 3D gene (Schubert et al., 2007). The second group that studied siRNA targeting CVB3 2A by Merl and co-workers evaluated antiviral activity of siRNA-2A (nts 3637-3657) in vitro and in highly susceptible type I interferon receptor-knockout mice. They found that siRNA-2A led to significant reduction of viral tissue titers, attenuated tissue damage and prolonged survival of mice (Merl et al., 2005). It is very interesting to point out that although the two groups used different targeting sequences within the 2A RNA, they all achieved high efficiency of antiviral effects. However, the later work by Racchi et al., which used these two siRNAs together to transfect HeLa cells and then infect with CVB3 did not potentiate the anti-CVB3 effect compared with an equimolar concentration of either siRNA (Racchi et al., 2009).

CVB3 RNA polymerase 3D is probably the most frequently used target for design of antiCVB3 siRNAs as it is the only viral enzyme involved in CVB3 RNA replication. To date, at least a half dozen of studies on 3D have been reported. The earlier in vitro investigations using either un-modified or LNA-modified siRNAs or plasmid vector-expressed shRNAs all achieved significant reduction of viral replication in CVB3-infected HeLa or Cos-7 cells (Ahn et al., 2005; Schubert et al., 2005; Schubert et al., 2007; Werk et al., 2005; Yuan et al., 2005). The in vivo evaluation using mouse models also showed very promising results. One study employing transient transfection for in vivo mouse models demonstrated that two of the six candidate siRNAs targeting 3D and VP1, respectively, exerted strong anti-CVB3 effects in viral replication, accompanied by attenuated pancreatic tissue damage (J. Y. Kim et al., 2007). Another in vivo study is the intravenous treatment of mice with an adeno-associated virus vector (AAV2.9) expressing a shRNA targeting 3D (Fechner et al., 2008). Intravenous injection of recombinant AAV2.9 significantly attenuated the cardiac dysfunction compared to vector-treated control mice on day 10 after CVB3 infection. Recently, a study by combination of soluble CAR receptor ( $\mathrm{sCAR}-\mathrm{Fc}$ ) and siRNA targeting $3 \mathrm{D}$ achieved a synergistic effect in antiviral effect in human myocardial fibroblast cell culture (Werk et al., 2009).

Other less frequently used CVB3 target genes are protease 3C, structural protein VP1 and non-structural protein $2 \mathrm{C}$. Like protease $2 \mathrm{~A}$, protease $3 \mathrm{C}$ also plays an important role in the viral life cycle by processing CVB3 polyproteins to generate mature individual structural and non-structural proteins after initial cleavage by 2A (Chau et al., 2007; L. E. C. Leong, Cornell, C. T., Semler, B. L., , 2002). One study designed three siRNAs targeting genes encoding 3C, 2A and 3D of CVB4. Evaluation by transfection of rhabdomyosarcoma (RD) cells demonstrated that siRNA-3C was the most potent siRNA among these three in inhibition of CVB4 replication. This antiviral activity was followed by siRNAs targeting 3D and 2A (Tan, 2010). The difference in efficiency of these siRNAs was discussed by these authors and they proposed that this may be due to the differences in function of these viral enzymes, which are encoded by these regions: the $3 \mathrm{C}$ region encodes a protease $3 \mathrm{C}$ which is responsible for majority of the cleavage of the viral polyprotein (L. E. C. Leong, Cornell, C. T., Semler, B. L., , 2002) and 3C as well as its precursor 3CD also plays an important role at the level of viral transcription (Parsley et al., 1999). Protease 3C has been shown to be critical for interaction with the cloverleaf structures found at the 5'UTR of the viral genome to 
deliver the 3D to the replication complex (L. E. Leong et al., 1993). They also indicated that since the function of $3 \mathrm{C}$ is required prior to $3 \mathrm{D}$, a down-regulation in $3 \mathrm{C}$ would have a detrimental effect on viral transcription as available 3D would not be able to carry out replication of CVB4 replication without the assistance of 3C. The authors' discussion seems to be reasonable; however, according to the order (timing) of action for these enzymes, $2 \mathrm{~A}$ cleaves the polyprotein prior to $3 C^{\prime}$ s cleavage. For this situation, it may be difficult to explain why the siRNAs targeting 2A did not achieve a more efficacious anti-CVB3 activity than siRNA targeting $3 \mathrm{C}$. Obviously, many issues relating to the mechanisms of action need to be further studied. However, according to the present reports, one point is clear that 2A, 3C and 3D are three important targets for design anti-CVB3 siRNAs.

Viral structural protein VP1 was also a selected target for testing anti-CVB3 siRNAs; however, the data from literature often showed a lower effectiveness of the siRNA targeting this structural gene as compared to that targeting other genes (Ahn et al., 2005; J. Y. Kim et al., 2007; Yuan et al., 2005). Due to the absence of a proof-reading activity in 3D, the mutation rate for RNA viruses is as high as $10^{-3}-10^{-4}$ (Cann, 2005). Thus, in recent years, the discovery of the occurrence of escape mutants due to siRNA treatment of $\mathrm{HCV}$, poliovirus and HIV infections (Boden et al., 2003; Gitlin et al., 2005; Wilson\& Richardson, 2005) greatly encouraged researchers to search for new approaches to counteract the drug resistance. One direction is the application of multiple distinct siRNAs or a siRNA pool to target more than one target genes of the virus (Merl\& Wessely, 2007; Nygardas et al., 2009). The other direction is the identification of conserved cis-acting replication elements (CRE) (van Ooij et al., 2006). Theoretically, the 5'- and 3'-UTRs are the ideal target regions for siRNAs as they harbor a number of conserved cis-acting elements. However, studies with poliovirus and CVB3 found that siRNA residing in these regions are less efficient than siRNAs targeting on other regions (e.g., the coding region and particularly the non-structural coding region) in inducing antiviral activity (Gitlin\& Stone\& Andino, 2005; Merl\& Wessely, 2007; Saleh et al., 2004; Yuan et al., 2005). This low antiviral potency seems to be due to the highly ordered structure of the UTRs itself, as well as the formation of the protein-RNA complexes in the region, which may block the access of the RISC complexes to its target sequences. To address this issue, Lee and coworkers selected a CRE within the coding region of $2 \mathrm{C}$. Evaluation in HeLa cells demonstrated the downregulation of virus replication and attenuation of cytotoxicity in various strains and clinic isolates. Cells treated with this siRNA were resistant to the emergence of viable escape mutants and showed sustained antiviral ability (Lee et al., 2007). Based on this study, a similar experiment using siRNA targeting CRE of CVA24 2C was conducted and the authors reported the similar observations (Jun et al., 2008). These findings from in vitro studies were further solidified by in vivo evaluation, in which recombinant lentivirus was employed to express shRNAs targeting the CRE of CVB3 2C. Mice injected intraperitoneally with recombinant lentiviruses had significant reductions in viral titers, viral myocarditis and proinflammatory cytokines as well as improved survival rate, after being challenged with CVB3 (Y. J. Kim et al., 2008). Recently, this CRE was further confirmed for a number of enteroviruses, by using a novel program and in vitro evaluation (Lee et al., 2009).

\subsubsection{Targeting host cellular genes}

Another approach to fight the drug resistance caused by escape mutants is the selection of therapeutic targets within the host cellular genes that are necessary for virus entry or viral 
replication. In this regard, the CAR receptor which is shared by CVB3 and adenovirus is an attractive candidate since both CVB3 and adenovirus are considered as the common causal agents of myocarditis. To date, two studies have been reported to silence CAR expression with specific siRNAs. One study reported that transfection of HeLa cells with siRNAs, siCAR2 or siCAR9, almost completely silenced the expression of CAR and that further analysis by viral plaque assay revealed $\sim 60 \%$ reduction of CVB3 particle formation (Werk et al., 2005). Another study using cardiac-derived HL-1 cell line and primary neonatal cardiomyocytes (PNCMs) demonstrated that treatment with recombinant adenoviruses expressing shRNAs against CAR resulted in almost completely silencing of CAR expression in both HL-1 cells and PNCMs. CAR knockout resulted in inhibition of CVB3 infections by up to $97 \%$ in HL-1 and up to $90 \%$ in PNCMs. Adenoviruses were inhibited by only $75 \%$ in HL-1, but up to $92 \%$ in PNCMs (Fechner et al., 2007).

Another host gene, the tissue inhibitor of matrix metalloproteinase-1 (TIMP-1), has been suggested to be a potential target for siRNA to ameliorate CVB3-induced myocarditis. This suggestion is based on the investigation of Crocker and colleagues on a new role of TIMP-1 in exacerbating CVB-induced myocarditis (Crocker et al., 2007). They found that TIMP-1 expression was induced in the myocardium by CVB3 infection. Surprisingly, TIMP-1 knockout mice exhibited a profound attenuation of myocarditis, with increased survival. The amelioration of disease in TIMP-1 knockout mice was not attributable to either an altered T-cell response to the virus or to reduced viral replication. These data allowed the authors to propose and prove a novel function for TIMP-1: its highly localized up-regulation might arrest the matrix metalloproteinase (MMP)-dependent migration of inflammatory cells at the sites of infection thereby anatomically focusing the adaptive immune response. Finally, the benefits of TIMP-1 blockage in treating CVB myocarditis were confirmed by administration of siRNAs targeting TIMP-1, which diminished CVB3-induced myocarditis. However, this improvement of the disease is not due to the changes of viral titers, as demonstrated by viral plaque assay (Crocker et al., 2007).

Recently, the active investigations on CVB3-induced signal transduction pathways have provided new avenues for the search of therapeutic targets for the treatment of myocarditis. Since CVB3, like other picornaviruses, requires the activation of certain signal pathways for initiating their life cycle, inactivation of some signal molecules in the signal cascade with specific siRNAs would block CVB3 replication. Such kind of studies that have been documented thus far include i) the knockdown of ubiquitin expression by siRNAs to downregulate the ubiquitination and subsequent alteration of protein function and/or degradation (Si et al., 2008); ii) silencing of proteosome activator REGY to inhibit the REGYmediated degradation of several important intracellular proteins (Gao, 2010), such as cyclindependent kinase inhibitors p21, p16 and p19 and tumor suppressor p53; and iii) knockdown of genes critical important for autophagy formation, these genes include ATG7, Beeclin-1 and VPS34 (J. Wong et al., 2008). Although these target genes mentioned above have been tested in vitro using specific siRNAs in signal transduction studies and showed promising outcomes, their potential serving as a therapeutic target for treatment of CVB3 infection needs a further evaluation by pharmacological study in animal models.

\subsection{Anti-CVB3 artificial miRNAs}

miRNAs are a group of recently discovered new regulators of gene expression. These endogenous regulators control one third of human gene expression (Bartel, 2009; Q. Liu, 
Paroo, Z., 2010). Thus, endogenous miRNAs are important targets for gene therapy and artificial miRNAs (AmiRNA) are useful tools for inhibiting disease-causing gene expression (Z. Liu et al., 2008; Sall et al., 2008). In this regard, although numerous studies have been documented for treatment of cancers, cardiovascular diseases, genetic diseases and other viral infections, only one study on anti-CVB3 from our group has been published so far. Here, I briefly summarize our work on design and evaluation of anti-CVB3 AmiRNAs (Ye et al., 2011). We constructed three short hairpin AmiRNAs (AmiR-1, -2 and -3) targeting the stem-loop of the 3'UTR of CVB3 with mismatches at the middle region of the target. Transfection of HeLa cells showed over-expression of these mature AmiRNAs as determined by real time quantitative RT-PCR. After these AmiRNA-expressing cells were infected with CVB3, the viral titers were reduced $\sim 100$ folds in cell cultures treated with AmiR-1 or AmiR-2 but not that treated with AmiR-3, at $24 \mathrm{~h}$ post infection. Mutational analysis of the targeting sites of AmiRNAs demonstrated that the central region but not the seed region of AmiRNAs is more tolerant to target mutation. In this study we also performed targeted delivery of the AmiRNAs to host cells through ligand-receptor interactions, which will be discussed in next section.

\section{Drug delivery}

NA-based agents are inefficiently taken up by mammalian cells and would therefore benefits from additional vehicles or modifications that facilitate drug delivery. Depending on transient delivery or long-term treatment, the delivery approaches can be divided into non-viral delivery of chemically synthesized agents and viral delivery of drug-expressing cassettes (Table 1). For the non-viral delivery measures, they can be further divided into unspecific and cell-type specific delivery. The former method has been widely used for delivery of many chemically synthesized ASONs, ribozymes and siRNAs as well as plasmids encoding shRNAs through transfection of tissue culture cells, hydrodynamic transduction/transfection of mice or intravenous (IV) injection of mice via tails using cationic lipoplexes or liposomes. The successful examples for inhibition of viral pathogens of myocarditis includes deliveries of i) ASONs targeting CVB3 IRES (Yuan et al., 2006) and both ends of the CVB3 genome (A. Wang et al., 2001), ii) siRNAs targeting CVB3 2A (Merl et al., 2005; Yuan et al., 2005) and 3D (Ahn et al., 2005; Schubert et al., 2005; Schubert et al., 2007), iii) plasmids expressing shRNAs targeting 3D and VP1 (J. Y. Kim et al., 2007) and vi) ribozymes targeting HCV RNA (Gonzalez-Carmona et al., 2006). For the cell-type specific method, proper modification and conjugation of 'naked' raw therapeutic molecules are required to achieve targeted delivery. The different chemical modifications described earlier for ASONs are applicable to all NA-based agents. The conjugation of these antivirals can be achieved by covalent linkage of a ligand to the molecules, which enables the drug internalization via specific interactions between the ligand and its receptor. The ligands can be an antibody, vitamin, short peptide, RNA aptamer, folic acid, etc. The details were reviewed elsewhere (X. Ye \& Yang, 2009). By this strategy, we have specifically delivered siRNAs targeting CVB3 2A to HeLa (cancer) cells, a cell line susceptible to CVB3, through interactions between folate and its receptor highly expressed on the surface of all cancer cells but not the normal cells (Zhang et al., 2009). This study was carried out by covalent linkage of the siRNA targeting CVB3 2A to a bacterial phage-29 packaging RNA (pRNA). This small pRNA ( 170 nts) can form dimer, trimer and hexamer by base pairing through its 


\begin{tabular}{|c|c|c|c|c|}
\hline Category & Target & Model system & Delivery route & Reference \\
\hline PS-ASON & $\begin{array}{l}5^{\prime} \& 3^{\prime} \text { UTRs, IRES, } \\
\text { start codon, }\end{array}$ & HeLa cell, mice & Transfection & Wang 2003 \\
\hline PS-ASON & 3 'end of CVB3 & HL-1 cells, mice & $\begin{array}{l}\text { Transfection, } \\
\text { IV injection }\end{array}$ & Yuan 2004 \\
\hline MOP-ASON & $\begin{array}{l}\text { IRES, 5' \& } 3^{\prime} \text { UTR, } \\
\text { start codon, } \\
\text { minus strand }\end{array}$ & $\begin{array}{l}\text { HeLa, HL-1 cell, } \\
\text { mice }\end{array}$ & $\begin{array}{l}\text { Transfection } \\
\text { and IV injection }\end{array}$ & Yuan 2006 \\
\hline CpG oligoer & no & PBMCs & Treatment & Cong 2007 \\
\hline SiRNA & 2A, VP1,3D & HeLa cells & Transfection & Yuan 2005 \\
\hline siRNA & $\begin{array}{l}2 \mathrm{~A} \\
2 \mathrm{~A} \\
2 \mathrm{~A}\end{array}$ & $\begin{array}{l}\text { HeLa cells, mice } \\
\text { HeLa cells } \\
\text { HeLa cells }\end{array}$ & $\begin{array}{l}\text { Hydrodynamic, } \\
\text { Transfection } \\
\text { pRNA vector }\end{array}$ & $\begin{array}{l}\text { Merl } 2005 \\
\text { Racchi } 2009 \\
\text { Zhang } 2009\end{array}$ \\
\hline shRNA & $3 \mathrm{D}$ & HeLa cells & $\begin{array}{l}\text { Transfection of } \\
\text { double expression } \\
\text { plasmid }\end{array}$ & Schubert 2005 \\
\hline SiRNA & 3D, VP1 & HeLa cells & Transfection & Ahn 2005 \\
\hline LNA-siRNA & $3 \mathrm{D}$ & Cos-7 cells & Transfection & Schubert 2007 \\
\hline siRNA & siRNA pool & LLC-MK2 cells & Transfection & Nygardas 2009 \\
\hline shRNA & VP1, 3D, $5^{\prime} \& 3^{\prime}$ UTR & Cos-7 cells, mice & $\begin{array}{l}\text { hydrodynamic, } \\
\text { transfectin of } \\
\text { plasmid }\end{array}$ & Kim J-Y 2007 \\
\hline $\begin{array}{l}\text { siRNA \& } \\
\text { SCAR-FC }\end{array}$ & $3 \mathrm{D}$ & HMF & Transfection & Werk D 2009 \\
\hline shRNA & $3 \mathrm{D}$ & $\begin{array}{l}\text { HeLa, PNCMs, } \\
\text { Mice }\end{array}$ & $\begin{array}{l}\text { Transduction, IV, } \\
\text { AAV vector }\end{array}$ & Fechner 2008 \\
\hline siRNA & & & & \\
\hline (CVB4) & $3 \mathrm{D}, 3 \mathrm{C}, 2 \mathrm{~A}$ & RD cells & Transfection & Tan, 2010 \\
\hline shRNÁ & $2 \mathrm{C}$ & Mice & $\begin{array}{l}\text { IP injection, } \\
\text { lentivirus vecotr }\end{array}$ & Lee 2007 \\
\hline shRNA & & & & \\
\hline (CVA24) & $2 \mathrm{C}$ & HeLa, HCC & $\begin{array}{l}\text { Transfection, } \\
\text { plasmid }\end{array}$ & Jun 2008 \\
\hline $\begin{array}{l}\text { siRNA } \\
\text { (enteroviruses) }\end{array}$ & $2 \mathrm{C}$ & HeLa, Vero cells & Transfection & Lee 2009 \\
\hline ShRNA & CAR & HL-1, PNCMs & Adenovirus vector & Fecherner 2007 \\
\hline siRNA & TIMP-1 & Mice & IV injection & Crocker 2007 \\
\hline siRNA & CAR, 3D & HeLa,Cos-7 cells & Transfection & Werk 2005 \\
\hline siRNA & Ubiquitin & HeLa cells & Transfection & Si 2008 \\
\hline siRNA & ATG7, Beclin-, VPS34 & HeLa cells & Transfection & Wong 2008 \\
\hline siRNA & $\begin{array}{l}\text { Proteasome activator } \\
\text { REGY }\end{array}$ & HeLa cells & Transfection & Gao G 2010 \\
\hline
\end{tabular}

Abbreviations: LNA: locked nucleic acid; RD: rhabdomyosarcoma; PBMC: peripheral blood mononuclear cell; HMF: human myocardial fibroblast; HCC: human conjunctive cell.

Table 1. NA-based agents for the treatment of CVB3 infection.

left- and right-hand loops (P. Guo, 2002) (Fig. 3). Thus, this pRNA multimer can carry multiple siRNAs and has the potential to overcome issues associated with drug resistance of viruses (P. Guo, 2005). In addition, this small pRNA vector has lower immunogenicity than big DNA vectors. Thus it is a safe vehicle for transportation of antiviral drugs (S. Guo et al., 2006). We labeled, by in vitro transcription, the 5'end of the pRNA with AMP-folic acid, 
which guided the targeted delivery of siRNAs via ligand-receptor interactions and achieved strong inhibition of CVB3 replication (Zhang et al., 2009). The effectiveness of this strategy on targeted delivery of NA-based drugs was further solidified in targeted delivery of AmiRNAs to inhibit CVB3 replication (X. Ye, Liu, Z., Hemida, G. M., and Yang, D. C., 2011). Viral vector-mediated delivery of NA-based agents is another promising approach for treatment of persistent infection such as CVB3, HCV and many other viruses. This is because that the vector-encoded shRNA can produce relative long-term and continuous silencing. Most viral vectors are modified viruses, which can be applied to deliver a cargo sequence to cells. Currently the most commonly used viral vectors for the delivery of NAbased drugs are derived from the adenovirus, adeno-associated viruses (AAV) and lentiviruses. These vectors have been widely used and have achieved exciting promise (Fechner et al., 2008; Henry et al., 2006; Kuhlmann et al., 2008). Recent trends in further improvement of these vectors focus on modifications of their structure to increase the capability for targeted delivery. The efforts of this goal can be summarized into three categories (X. Ye \& Yang, 2009): i) the genetic and chemical modifications of the vector to express a unique chimeric surface protein, such as adenovirus capsid proteins: fiber knob, penton and hexon. The common strategy is the insertion of a foreign peptide into fiber knob, which enables the vector to be capable of binding the specific cellular receptor (Koizumi et al., 2003; Mizuguchi\& Hayakawa, 2002); ii) incorporation of heterologous protein from another virus with a restricted range of tissue tropism to the viral envelope; this approach is also called pseudotyping. An example of this strategy is the pseudotyping of lentivirus vector with the neurotropic rabies virus glycoprotein allows retro-axonal and trans-synoptic spread, thereby enhancing the transgene expression within the brain (L. F. Wong et al., 2004); and iii) the application of a tissue-specific promoter to express the vector-carried gene in a specific organ or cell type. An impressive finding has been reported regarding the utilization of cardiac myosin light chain $2 \mathrm{v}$ promoter and the hypoxia-response element by AAV vector to express vascular endothelial growth factor, an angiogenic factor, specifically in myocardium, leading to cardiac functional improvement (Su et al., 2004). Here we will briefly discuss the delivery of NA-based antivirals using these viral vectors for CVB3 infection.

Adenovirus is known to share the CAR receptor with CVB3. This receptor is highly expressed on the surface of cardiomyocytes. Thus, adenovirus-derived vector is an ideal carrier for delivery of NA-based antivirals to the heart. This vector has successfully delivered shRNAs targeting the CAR gene in a cardiac-derived HL-1 cell line and isolated PNCMs, resulting in the strong reduction of replication of both CVB3 and adenovirus (Fechner et al., 2007). Lentivirus vectors are derived from HIV. They have the ability to transduce quiescent as well as proliferating cells, thus increasing their therapeutic ranges. Particularly, after pseudotyping with G glycoprotein of vesicular stomatitis virus, they can transduce almost any cell type (Kurreck, 2009). Kim Y-J et al. constructed recombinant lentiviruses that express shRNAs targeting the CRE within CVB3 2C. Intraperitoneal injection of mice with these viruses clearly showed a protective effect against viral myocarditis by elimination of CVB3 infection and reducing pro-inflammatory cytokines, such as IL6 and INF-a. (Y. J. Kim et al., 2008). AAVs are attractive vectors for gene transfer since they efficiently transduce target cells and are nonpathogenic for humans. Fechner $\mathrm{H}$ et al. have employed a pseudotyped AAV2.9 vector, carrying the most cardiotropic AAV capsid currently known to successfully transduce PNCMs. This vector expressed siRNAs targeting CVB3 3D and reduced CVB3 replication by $>3 \log _{10}$ steps. Further evaluation by 
intravenous injection of mice demonstrated significant reduction of virus titers and improvement of heart function compared to the control. This study showed for the first time that intravenously injected AAV2.9 has the potential to target RNAi to the heart and suggests AVV2.9-shRNA vectors as a novel therapeutic approach for cardiac disorders (Fechner et al., 2008).

A

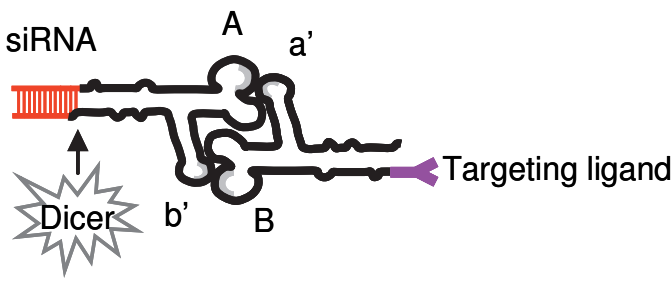

B

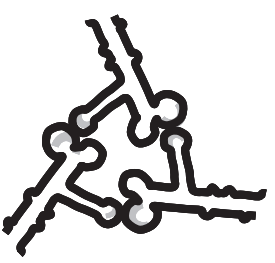

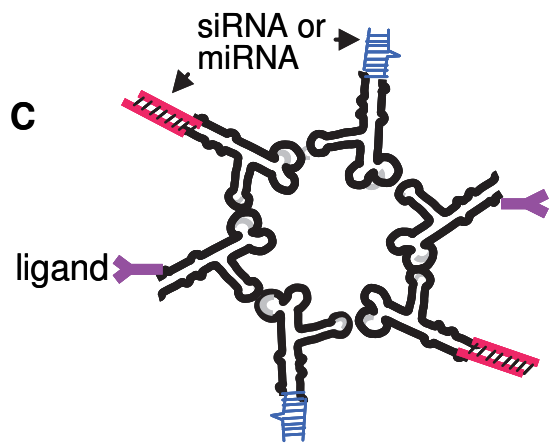

Fig. 3. Structural schematic of packaging RNA (pRNA) multimers as a drug targeted delivery vehicle. (A) pRNA dimer forms through the base-paring between the loops of an $A^{\prime} b-p R N A-s i R N A$ and a B'a-pRNA-ligand. The shaded areas on the loops indicate the basepair interactions between the monomers. siRNA is released when intracellular Dicer cleaves the dsRNA, which is indicated by an arrow. (B) pRNA trimers can be stoichiometrically formed by hand-in-hand loop interactions, which contains 1:1:1 of their linked conjugates. (C) hexamers allow for a customizable, combined therapy where multiple drugs may be added to the same complex.

\section{Concluding remarks}

NA-based gene silencing techniques have been successfully used in drug development. The major progress on ASON research is the chemical modifications and ligand conjugation to enhance drug stability and efficacy of delivery. The emergence of RNAi-mediated gene silencing techniques further provided new hope for this regard. Basically, siRNA silencing techniques can be used against any viral infection. Two major obstacles must, however, be overcome before it can become a broadly applicable standard therapy: the question of their specificity and efficient delivery to target cells. As siRNA can potentially cause off-site targeting and activate the immune system, minimizing the undesired effects must be considered in the drug design. Immense efforts have been undertaken to develop carrier 
system with which siRNAs can be delivered to their target cells. Despite great advances in the last years, further developments are still required to get systematically applied siRNAs to their required sites of action. Here, viral vectors systems for shRNA expression cassettes offer additional options for efficient and organ-specific delivery. However, this approach must be first overcome the reservations based on the negative experience with gene therapy. As discussed earlier, pRNA is a promising vehicle for targeted delivery of NA-based therapeutic molecules. For treatment of myocarditis, a myocardium-specific ligand such as peptides from the CVB3 antireceptor protein or RNA apatamers of cardiomyocytes should be identified, which will be used to replace folic acid on the pRNA vector.

Very recent advances in the understanding of miRNA biology and particularly their association with the molecular pathogenesis of a variety of diseases have served as a theoretical basis for drug development. On the one hand, miRNA, as one of the key factors for regulation of viral replication, tissue tropism and latency, are the ideal targets for inhibition. In this regard, construction of mRNAs that contain multiple tandem binding sites of a given miRNA may be useful to produce decoys or "miRNA sponges" to inhibit the function of a specific miRNA. In addition, chemically synthesized antisense RNA oligomers ('antagomirs') targeting a miRNA of interest could be also a promising approach to inhibit miRNA activity (Ebert et al., 2007; Krutzfeldt et al., 2005). Other strategies include i) overexpression of specific miRNAs using an expression vector to achieve a long-term effect of reversing the imbalance of miRNA expression caused by infections, and ii) introduction of pre-miRNA mimetics for transient replacement of a down-regulated miRNA. On the other hand, miRNA can serve as a useful tool for therapy. Since miRNA is tolerable to target mutation at its center region, application of multiple artificial miRNAs to target the 3'UTR and/or other regions of CVB3 RNA may improve the drug resistance. Given the immense interest in NA-based drug research and the rapid progress made in this field and other areas such as nano-biotechnology for drug delivery, the coming years are likely to see an increasing range of clinical applications, particularly for the RNAi-based drug candidates. The realization of the potential of NA-based therapies to address human viral pathogens suggests that this field has a very promising future.

\section{Acknowledgements}

My special thanks go to my students, Postdoctoral Fellows and Research Associates, whose tireless efforts contributed to the advances of my research group. I also thank Paul Hanson for his critical reading of this manuscript and Xin Ye for his help on preparing the manuscript. The work was supported by grants from the Canada Institute of Health Research and the Heart and Stroke Foundation of British Columbia \& Yukon.

\section{References}

Ahn, J., Jun, E. S., Lee, H. S., Yoon, S. Y., Kim, D., Joo, C. H., Kim, Y. K.\& Lee, H. (2005). A small interfering RNA targeting coxsackievirus B3 protects permissive HeLa cells from viral challenge. The Journal of Virology, 79(13), 8620-8624.

Amantana, A.\& Iversen, P. L. (2005). Pharmacokinetics and biodistribution of phosphorodiamidate morpholino antisense oligomers. Current Opinion in Pharmacology, 5(5), 550-555. 
Andreoletti, L., Leveque, N., Boulagnon, C., Brasselet, C.\& Fornes, P. (2009). Viral causes of human myocarditis. Archives Of Cardiovascular Diseases, 102(6-7), 559-568.

Bartel, D. P. (2004). MicroRNAs: genomics, biogenesis, mechanism, and function. Cell, 116(2), 281-297.

Bartel, D. P. (2009). MicroRNAs: target recognition and regulatory functions. Cell, 136(2), 215-233.

Bennasser, Y., Le, S. Y., Benkirane, M.\& Jeang, K. T. (2005). Evidence that HIV-1 encodes an siRNA and a suppressor of RNA silencing. Immunity, 22(5), 607-619.

Berkhout, B.\& Jeang, K. T. (2007). RISCy business: MicroRNAs, pathogenesis, and viruses. The Journal of Biological Chemistry, 282(37), 26641-26645.

Bertrand, J. R., Pottier, M., Vekris, A., Opolon, P., Maksimenko, A.\& Malvy, C. (2002). Comparison of antisense oligonucleotides and siRNAs in cell culture and in vivo. Biochemical and Biophysical Research Communications, 296(4), 1000-1004.

Blauwet, L. A., Cooper, L. T. (2010). Myocarditis. Progress in Cardiovascular Diseases, 52, 274288.

Boden, D., Pusch, O., Lee, F., Tucker, L.\& Ramratnam, B. (2003). Human immunodeficiency virus type 1 escape from RNA interference. The Journal of Virology, 77(21), 1153111535.

Bowles, N. E., Ni, J., Kearney, D. L., Pauschinger, M., Schultheiss, H. P., McCarthy, R., Hare, J., Bricker, J. T., Bowles, K. R.\& Towbin, J. A. (2003). Detection of viruses in myocardial tissues by polymerase chain reaction. evidence of adenovirus as a common cause of myocarditis in children and adults. Journal of the American College of Cardiology, 42(3), 466-472.

Brennecke, J., Stark, A., Russell, R. B.\& Cohen, S. M. (2005). Principles of microRNA-target recognition. PLoS Biology, 3(3), e85.

Cann, A. (2005). Genome. 4th ed. In "Principles of Molecular Virology", pp. 78-79. Elsevier Academic Press, 9780120887897, San Diego, CA.

Cardarelli, F., Serresi, M., Bizzarri, R., Giacca, M.\& Beltram, F. (2007). In vivo study of HIV-1 Tat arginine-rich motif unveils its transport properties. Molecular Therapy, 15(7), 1313-1322.

Carthew, R. W.\& Sontheimer, E. J. (2009). Origins and Mechanisms of miRNAs and siRNAs. Cell, 136(4), 642-655.

Caudy, A. A., Ketting, R. F., Hammond, S. M., Denli, A. M., Bathoorn, A. M., Tops, B. B., Silva, J. M., Myers, M. M., Hannon, G. J.\& Plasterk, R. H. (2003). A micrococcal nuclease homologue in RNAi effector complexes. Nature, 425(6956), 411-414.

Chau, D. H., Yuan, J., Zhang, H., Cheung, P., Lim, T., Liu, Z., Sall, A.\& Yang, D. (2007). Coxsackievirus B3 proteases $2 \mathrm{~A}$ and $3 \mathrm{C}$ induce apoptotic cell death through mitochondrial injury and cleavage of eIF4GI but not DAP5/p97/NAT1. Apoptosis, 12(3), 513-524.

Cheung, P., Lim, T., Yuan, J., Zhang, M., Chau, D., McManus, B.\& Yang, D. (2007). Specific interaction of HeLa cell proteins with coxsackievirus B3 3'UTR: La autoantigen binds the $3^{\prime}$ and 5'UTR independently of the poly(A) tail. Cellular Microbiology, 9(7), 1705-1715.

Cohen, C. J., Shieh, J. T., Pickles, R. J., Okegawa, T., Hsieh, J. T.\& Bergelson, J. M. (2001). The coxsackievirus and adenovirus receptor is a transmembrane component of the tight junction. Proceedings of the National Academy of Sciences U S A, 98(26), 15191-15196.

Cong, Z., Wan, M., Wu, X., Wang, L., Hu, X., Yang, F., Bao, M., Zhang, X., Chen, J.\& Yu, Y. (2007). A CpG oligodeoxynucleotide inducing anti-coxsackie B3 virus activity in 
human peripheral blood mononuclear cells. FEMS Immunology and Medical Microbiology, 51(1), 26-34.

Cooper, L. T., Baughman, K. L., Feldman, A. M., Frustaci, A., Jessup, M., Kuhl, U., Levine, G. N., Narula, J., Starling, R. C., Towbin, J.\& Virmani, R. (2007). The role of endomyocardial biopsy in the management of cardiovascular disease: a scientific statement from the American Heart Association, the American College of Cardiology, and the European Society of Cardiology. Endorsed by the Heart Failure Society of America and the Heart Failure Association of the European Society of Cardiology. Journal of the American College of Cardiology, 50(19), 1914-1931.

Cooper, L. T., Jr. (2009). Myocarditis. The New England Journal of Medicine, 360(15), 1526-1538.

Cotten, M., Oberhauser, B., Brunar, H., Holzner, A., Issakides, G., Noe, C. R., Schaffner, G., Wagner, E.\& Birnstiel, M. L. (1991). 2'-O-methyl, 2'-O-ethyl oligoribonucleotides and phosphorothioate oligodeoxyribonucleotides as inhibitors of the in vitro U7 snRNP-dependent mRNA processing event. Nucleic Acids Research, 19(10), 26292635.

Crocker, S. J., Frausto, R. F., Whitmire, J. K., Benning, N., Milner, R.\& Whitton, J. L. (2007). Amelioration of coxsackievirus B3-mediated myocarditis by inhibition of tissue inhibitors of matrix metalloproteinase-1. The American Journal of Pathology, 171(6), 1762-1773.

Crooke, S. T., Graham, M. J., Zuckerman, J. E., Brooks, D., Conklin, B. S., Cummins, L. L., Greig, M. J., Guinosso, C. J., Kornbrust, D., Manoharan, M., Sasmor, H. M., Schleich, T., Tivel, K. L.\& Griffey, R. H. (1996). Pharmacokinetic properties of several novel oligonucleotide analogs in mice. Journal of Pharmacology and Experimental Therapeutics, 277(2), 923-937.

Cullen, B. R. (2006). Is RNA interference involved in intrinsic antiviral immunity in mammals? Nature Immunology, 7(6), 563-567.

Dennert, R., Crijns, H. J.\& Heymans, S. (2008). Acute viral myocarditis. European Heart Journal, 29(17), 2073-2082.

Doench, J. G., Petersen, C. P.\& Sharp, P. A. (2003). siRNAs can function as miRNAs. Genes $\mathcal{E}$ Development, 17(4), 438-442.

Ebert, M. S., Neilson, J. R.\& Sharp, P. A. (2007). MicroRNA sponges: competitive inhibitors of small RNAs in mammalian cells. Nature Methods, 4(9), 721-726.

Fechner, H., Pinkert, S., Wang, X., Sipo, I., Suckau, L., Kurreck, J., Dorner, A., Sollerbrant, K., Zeichhardt, H., Grunert, H. P., Vetter, R., Schultheiss, H. P.\& Poller, W. (2007). Coxsackievirus B3 and adenovirus infections of cardiac cells are efficiently inhibited by vector-mediated RNA interference targeting their common receptor. Gene Therapy, 14(12), 960-971.

Fechner, H., Sipo, I., Westermann, D., Pinkert, S., Wang, X., Suckau, L., Kurreck, J., Zeichhardt, H., Muller, O., Vetter, R., Erdmann, V., Tschope, C.\& Poller, W. (2008). Cardiac-targeted RNA interference mediated by an AAV9 vector improves cardiac function in coxsackievirus B3 cardiomyopathy. Journal of Molecular Medicine, 86(9), 987-997.

Freimuth, P., Philipson, L.\& Carson, S. D. (2008). The coxsackievirus and adenovirus receptor. Current Topics in Microbiology and Immunology, 323, 67-87.

Frese, M., Bartenschlager, R. (2006). Inhibition of hepatitis C virus by nucleic acid-based antiviral approaches. In "New Concept of Antiviral Therapy" (E. a. H. Bogner, A., Ed.), pp. 47-86. Springer, 0387310460.

Frustaci, A., Chimenti, C., Calabrese, F., Pieroni, M., Thiene, G.\& Maseri, A. (2003). Immunosuppressive therapy for active lymphocytic myocarditis: virological and 
immunologic profile of responders versus nonresponders. Circulation, 107(6), 857863.

Gao, G., Wong, J., Zhang, J., Mao, I., Shravah, J, Wu, Y., Xiao, A., Li, X., Luo, H. (2010). Proteasome activator REGgamma enhances coxsackieviral infection by faciliating p53 degradation. The Journal of Virology, 84(21), 11056-11066.

Gitlin, L., Stone, J. K.\& Andino, R. (2005). Poliovirus escape from RNA interference: short interfering RNA-target recognition and implications for therapeutic approaches. $J$ Virol, 79(2), 1027-1035.

Gonzalez-Carmona, M. A., Schussler, S., Serwe, M., Alt, M., Ludwig, J., Sproat, B. S., Steigerwald, R., Hoffmann, P., Quasdorff, M., Schildgen, O.\& Caselmann, W. H. (2006). Hammerhead ribozymes with cleavage site specificity for NUH and NCH display significant anti-hepatitis $C$ viral effect in vitro and in recombinant HepG2 and CCL13 cells. Journal of Hepatology, 44(6), 1017-1025.

Grimson, A., Farh, K. K., Johnston, W. K., Garrett-Engele, P., Lim, L. P.\& Bartel, D. P. (2007). MicroRNA targeting specificity in mammals: determinants beyond seed pairing. Molecular Cell, 27(1), 91-105.

Groarke, J. M.\& Pevear, D. C. (1999). Attenuated virulence of pleconaril-resistant coxsackievirus B3 variants. Journal of Infectious Diseases, 179(6), 1538-1541.

Grunweller, A., Wyszko, E., Bieber, B., Jahnel, R., Erdmann, V. A.\& Kurreck, J. (2003). Comparison of different antisense strategies in mammalian cells using locked nucleic acids, 2'-O-methyl RNA, phosphorothioates and small interfering RNA. Nucleic Acids Research, 31(12), 3185-3193.

Guo, P. (2002). Structure and function of phi29 hexameric RNA that drives the viral DNA packaging motor: review. Progress in Nucleic Acid Research and Molecular Biology, 72, 415-472.

Guo, P. (2005). Bacterial virus phi29 DNA-packaging motor and its potential applications in gene therapy and nanotechnology. Methods in Molecular Biology, 300, 285-324.

Guo, S., Huang, F.\& Guo, P. (2006). Construction of folate-conjugated pRNA of bacteriophage phi29 DNA packaging motor for delivery of chimeric siRNA to nasopharyngeal carcinoma cells. Gene Therapy, 13(10), 814-820.

Haasnoot, J., Westerhout, E. M.\& Berkhout, B. (2007). RNA interference against viruses: strike and counterstrike. Nature Biotechnology, 25(12), 1435-1443.

Hannon, G. J. (2002). RNA interference. Nature, 418(6894), 244-251.

Haseloff, J.\& Gerlach, W. L. (1992). Simple RNA enzymes with new and highly specific endoribonuclease activities. 1988. Biotechnology, 24, 264-269.

Heasman, J. (2002). Morpholino oligos: making sense of antisense? Developmental Biology, 243(2), 209-214.

Hemida, M. G., Ye, X., Thair, S.\& Yang, D. (2010). Exploiting the therapeutic potential of microRNAs in viral diseases: expectations and limitations. Molecular Diagnosis $\mathcal{E}$ Therapy, 14(5), 271-282.

Henry, S. D., van der Wegen, P., Metselaar, H. J., Tilanus, H. W., Scholte, B. J.\& van der Laan, L. J. (2006). Simultaneous targeting of HCV replication and viral binding with a single lentiviral vector containing multiple RNA interference expression cassettes. Molecular Therapy, 14(4), 485-493.

Hoke, G. D., Draper, K., Freier, S. M., Gonzalez, C., Driver, V. B., Zounes, M. C.\& Ecker, D. J. (1991). Effects of phosphorothioate capping on antisense oligonucleotide stability, hybridization and antiviral efficacy versus herpes simplex virus infection. Nucleic Acids Research, 19(20), 5743-5748. 
Honda, T., Saitoh, H., Masuko, M., Katagiri-Abe, T., Tominaga, K., Kozakai, I., Kobayashi, K., Kumanishi, T., Watanabe, Y. G., Odani, S.\& Kuwano, R. (2000). The coxsackievirus-adenovirus receptor protein as a cell adhesion molecule in the developing mouse brain. Brain Research. Molecular Brain Research, 77(1), 19-28.

Jakobsen, M. R., Haasnoot, J., Wengel, J., Berkhout, B.\& Kjems, J. (2007). Efficient inhibition of HIV-1 expression by LNA modified antisense oligonucleotides and DNAzymes targeted to functionally selected binding sites. Retrovirology, 4, 29.

Jun, E. J., Nam, Y. R., Ahn, J., Tchah, H., Joo, C. H., Jee, Y., Kim, Y. K.\& Lee, H. (2008). Antiviral potency of a siRNA targeting a conserved region of coxsackievirus A24. Biochemical and Biophysical Research Communications, 376(2), 389-394.

Kaiser, L., Crump, C. E.\& Hayden, F. G. (2000). In vitro activity of pleconaril and AG7088 against selected serotypes and clinical isolates of human rhinoviruses. Antiviral Research, 47(3), 215-220.

Kim, J. Y., Chung, S. K., Hwang, H. Y., Kim, H., Kim, J. H., Nam, J. H.\& Park, S. I. (2007). Expression of short hairpin RNAs against the coxsackievirus B3 exerts potential antiviral effects in Cos-7 cells and in mice. Virus Research, 125(1), 9-13.

Kim, Y. J., Ahn, J., Jeung, S. Y., Kim, D. S., Na, H. N., Cho, Y. J., Yun, S. H., Jee, Y., Jeon, E. S., Lee, H.\& Nam, J. H. (2008). Recombinant lentivirus-delivered short hairpin RNAs targeted to conserved coxsackievirus sequences protect against viral myocarditis and improve survival rate in an animal model. Virus Genes, 36(1), 141-146.

Kindermann, I., Kindermann, M., Kandolf, R., Klingel, K., Bultmann, B., Muller, T., Lindinger, A.\& Bohm, M. (2008). Predictors of outcome in patients with suspected myocarditis. Circulation, 118(6), 639-648.

Klump, W. M., Bergmann, I., Muller, B. C., Ameis, D.\& Kandolf, R. (1990). Complete nucleotide sequence of infectious Coxsackievirus B3 cDNA: two initial 5 ' uridine residues are regained during plus-strand RNA synthesis. The Journal of Virology, 64(4), 1573-1583.

Knowlton, K. U. (2008). CVB infection and mechanisms of viral cardiomyopathy. Current Topics in Microbiology and Immunology, 323, 315-335.

Koizumi, N., Mizuguchi, H., Utoguchi, N., Watanabe, Y.\& Hayakawa, T. (2003). Generation of fiber-modified adenovirus vectors containing heterologous peptides in both the HI loop and C terminus of the fiber knob. The Journal of Gene Medicine, 5(4), 267-276.

Kore, A. R., Vaish, N. K., Kutzke, U.\& Eckstein, F. (1998). Sequence specificity of the hammerhead ribozyme revisited; the NHH rule. Nucleic Acids Research, 26(18), 4116-4120.

Krek, A., Grun, D., Poy, M. N., Wolf, R., Rosenberg, L., Epstein, E. J., MacMenamin, P., da Piedade, I., Gunsalus, K. C., Stoffel, M.\& Rajewsky, N. (2005). Combinatorial microRNA target predictions. Nature Genetics, 37(5), 495-500.

Krutzfeldt, J., Rajewsky, N., Braich, R., Rajeev, K. G., Tuschl, T., Manoharan, M.\& Stoffel, M. (2005). Silencing of microRNAs in vivo with 'antagomirs'. Nature, 438(7068), 685689.

Kuhl, U., Pauschinger, M., Noutsias, M., Seeberg, B., Bock, T., Lassner, D., Poller, W., Kandolf, R.\& Schultheiss, H. P. (2005a). High prevalence of viral genomes and multiple viral infections in the myocardium of adults with "idiopathic" left ventricular dysfunction. Circulation, 111(7), 887-893.

Kuhl, U., Pauschinger, M., Seeberg, B., Lassner, D., Noutsias, M., Poller, W.\& Schultheiss, H. P. (2005b). Viral persistence in the myocardium is associated with progressive cardiac dysfunction. Circulation, 112(13), 1965-1970. 
Kuhlmann, K. F., Gouma, D. J.\& Wesseling, J. G. (2008). Adenoviral gene therapy for pancreatic cancer: where do we stand? Digestive Surgery, 25(4), 278-292.

Kurreck, J. (2003). Antisense technologies. Improvement through novel chemical modifications. Eur J Biochem, 270(8), 1628-1644.

Kurreck, J. (2009). RNA interference: from basic research to therapeutic applications. Angewandte Chemie International Edition, 48(8), 1378-1398.

Kyto, V., Vuorinen, T., Saukko, P., Lautenschlager, I., Lignitz, E., Saraste, A.\& Voipio-Pulkki, L. M. (2005). Cytomegalovirus infection of the heart is common in patients with fatal myocarditis. Clinical Infectious Diseases, 40(5), 683-688.

Lacerra, G., Sierakowska, H., Carestia, C., Fucharoen, S., Summerton, J., Weller, D.\& Kole, R. (2000). Restoration of hemoglobin A synthesis in erythroid cells from peripheral blood of thalassemic patients. Proceedings of the National Academy of Sciences U S A, 97(17), 9591-9596.

Lecellier, C. H., Dunoyer, P., Arar, K., Lehmann-Che, J., Eyquem, S., Himber, C., Saib, A.\& Voinnet, O. (2005). A cellular microRNA mediates antiviral defense in human cells. Science, 308(5721), 557-560.

Lee, H. S., Ahn, J., Jee, Y., Seo, I. S., Jeon, E. J., Jeon, E. S., Joo, C. H., Kim, Y. K.\& Lee, H. (2007). Universal and mutation-resistant anti-enteroviral activity: potency of small interfering RNA complementary to the conserved cis-acting replication element within the enterovirus coding region. Journal of General Virology, 88(Pt 7), 2003-2012.

Lee, H. S., Ahn, J., Jun, E. J., Yang, S., Joo, C. H., Kim, Y. K.\& Lee, H. (2009). A novel program to design siRNAs simultaneously effective to highly variable virus genomes. Biochemical and Biophysical Research Communications, 384(4), 431-435.

Leong, L. E., Walker, P. A.\& Porter, A. G. (1993). Human rhinovirus-14 protease 3C (3Cpro) binds specifically to the 5'-noncoding region of the viral RNA. Evidence that 3Cpro has different domains for the RNA binding and proteolytic activities. The Journal of Biological Chemistry, 268(34), 25735-25739.

Leong, L. E. C., Cornell, C. T., Semler, B. L., (2002). Processing determinants and functions of cleavage products of picornavirus polyproteins. In "Molecular biology of Picornaviruses" (B. L. Semler, wimmer, E., Ed.), pp. 187-197. ASM Press, 9781555812102, Washington, DC.

Lewis, B. P., Shih, I. H., Jones-Rhoades, M. W., Bartel, D. P.\& Burge, C. B. (2003). Prediction of mammalian microRNA targets. Cell, 115(7), 787-798.

Liu, Q., Paroo, Z. (2010). Biochemical Principles of small RNA pathway. Annual Review of Biochemistry, 79, 295-319.

Liu, Z., Carthy, C. M., Cheung, P., Bohunek, L., Wilson, J. E., McManus, B. M.\& Yang, D. (1999). Structural and functional analysis of the $5^{\prime}$ untranslated region of coxsackievirus B3 RNA: In vivo translational and infectivity studies of full-length mutants. Virology, 265(2), 206-217.

Liu, Z., Sall, A.\& Yang, D. (2008). MicroRNA: An emerging therapeutic target and intervention tool. International Journal of Molecular Sciences, 9(6), 978-999.

Macejak, D. G., Jensen, K. L., Jamison, S. F., Domenico, K., Roberts, E. C., Chaudhary, N., von Carlowitz, I., Bellon, L., Tong, M. J., Conrad, A., Pavco, P. A.\& Blatt, L. M. (2000). Inhibition of hepatitis C virus (HCV)-RNA-dependent translation and replication of a chimeric $\mathrm{HCV}$ poliovirus using synthetic stabilized ribozymes. Hepatology, 31(3), 769-776.

Macejak, D. G., Jensen, K. L., Pavco, P. A., Phipps, K. M., Heinz, B. A., Colacino, J. M.\& Blatt, L. M. (2001). Enhanced antiviral effect in cell culture of type 1 interferon and ribozymes targeting HCV RNA. Journal of Viral Hepatitis, 8(6), 400-405. 
Maghsoudi, N., Tafreshi, N., Khodagholi, F., Zakeri, Z., Esfandiarei, M., Hadi-Alijanvand, H., Sabbaghian, M., Maghsoudi, A. H., Sajadi, M., Zohri, M., Moosavi, M.\& Zeinoddini, M. (2010). Targeting enteroviral 2A protease by a 16-mer synthetic peptide: inhibition of 2Apro-induced apoptosis in a stable Tet-on HeLa cell line. Virology, 399(1), 39-45.

Mahrholdt, H., Wagner, A., Deluigi, C. C., Kispert, E., Hager, S., Meinhardt, G., Vogelsberg, H., Fritz, P., Dippon, J., Bock, C. T., Klingel, K., Kandolf, R.\& Sechtem, U. (2006). Presentation, patterns of myocardial damage, and clinical course of viral myocarditis. Circulation, 114(15), 1581-1590.

Matsumori, A. (2005). Hepatitis C virus infection and cardiomyopathies. Circulation Research, 96(2), 144-147.

Matsumori, A., Shimada, T., Chapman, N. M., Tracy, S. M.\& Mason, J. W. (2006). Myocarditis and heart failure associated with hepatitis $C$ virus infection. Journal of Cardiac Failure, 12(4), 293-298.

Melchers, W. J., Hoenderop, J. G., Bruins Slot, H. J., Pleij, C. W., Pilipenko, E. V., Agol, V. I.\& Galama, J. M. (1997). Kissing of the two predominant hairpin loops in the coxsackie $B$ virus $3^{\prime}$ untranslated region is the essential structural feature of the origin of replication required for negative-strand RNA synthesis. The Journal of Virology, 71(1), 686-696.

Merl, S., Michaelis, C., Jaschke, B., Vorpahl, M., Seidl, S.\& Wessely, R. (2005). Targeting 2A protease by RNA interference attenuates coxsackieviral cytopathogenicity and promotes survival in highly susceptible mice. Circulation, 111(13), 1583-1592.

Merl, S.\& Wessely, R. (2007). Anti-coxsackieviral efficacy of RNA interference is highly dependent on genomic target selection and emergence of escape mutants. Oligonucleotides, 17(1), 44-53.

Mizuguchi, H.\& Hayakawa, T. (2002). Enhanced antitumor effect and reduced vector dissemination with fiber-modified adenovirus vectors expressing herpes simplex virus thymidine kinase. Cancer Gene Therapy, 9(3), 236-242.

Moazed, D. (2009). Small RNAs in transcriptional gene silencing and genome defence. Nature, 457(7228), 413-420.

Monia, B. P., Lesnik, E. A., Gonzalez, C., Lima, W. F., McGee, D., Guinosso, C. J., Kawasaki, A. M., Cook, P. D.\& Freier, S. M. (1993). Evaluation of 2'-modified oligonucleotides containing 2'-deoxy gaps as antisense inhibitors of gene expression. The Journal of Biological Chemistry, 268(19), 14514-14522.

Munroe, S. H. (1988). Antisense RNA inhibits splicing of pre-mRNA in vitro. EMBO J, 7(8), 2523-2532.

Napoli, C., Lemieux, C.\& Jorgensen, R. (1990). Introduction of a Chimeric Chalcone Synthase Gene into Petunia Results in Reversible Co-Suppression of Homologous Genes in trans. Plant Cell, 2(4), 279-289.

Nygardas, M., Vuorinen, T., Aalto, A. P., Bamford, D. H.\& Hukkanen, V. (2009). Inhibition of coxsackievirus B3 and related enteroviruses by antiviral short interfering RNA pools produced using phi6 RNA-dependent RNA polymerase. Journal of General Virology, 90(Pt 10), 2468-2473.

Otsuka, M., Jing, Q., Georgel, P., New, L., Chen, J., Mols, J., Kang, Y. J., Jiang, Z., Du, X., Cook, R., Das, S. C., Pattnaik, A. K., Beutler, B.\& Han, J. (2007). Hypersusceptibility to vesicular stomatitis virus infection in Dicer1-deficient mice is due to impaired miR24 and miR93 expression. Immunity, 27(1), 123-134.

Parker, J. S., Roe, S. M.\& Barford, D. (2005). Structural insights into mRNA recognition from a PIWI domain-siRNA guide complex. Nature, 434(7033), 663-666. 
Parsley, T. B., Cornell, C. T.\& Semler, B. L. (1999). Modulation of the RNA binding and protein processing activities of poliovirus polypeptide $3 \mathrm{CD}$ by the viral RNA polymerase domain. The Journal of Biological Chemistry, 274(18), 12867-12876.

Peracchi, A. (2004). Prospects for antiviral ribozymes and deoxyribozymes. Rev Med Virol, 14(1), 47-64.

Pinkert, S., Westermann, D., Wang, X., Klingel, K., Dorner, A., Savvatis, K., Grossl, T., Krohn, S., Tschope, C., Zeichhardt, H., Kotsch, K., Weitmann, K., Hoffmann, W., Schultheiss, H. P., Spiller, O. B., Poller, W.\& Fechner, H. (2009). Prevention of cardiac dysfunction in acute coxsackievirus B3 cardiomyopathy by inducible expression of a soluble coxsackievirus-adenovirus receptor. Circulation, 120(23), 2358-2366.

Racchi, G., Klingel, K., Kandolf, R.\& Grassi, G. (2009). Targeting of protease 2A genome by single and multiple siRNAs as a strategy to impair CVB3 life cycle in permissive HeLa cells. Methods \& Findings in Experimental \& Clinical Pharmacology, 31(2), 63-70.

Raschperger, E., Thyberg, J., Pettersson, S., Philipson, L., Fuxe, J.\& Pettersson, R. F. (2006). The coxsackie- and adenovirus receptor (CAR) is an in vivo marker for epithelial tight junctions, with a potential role in regulating permeability and tissue homeostasis. Experimental Cell Research, 312(9), 1566-1580.

Reisdorph, N., Thomas, J. J., Katpally, U., Chase, E., Harris, K., Siuzdak, G.\& Smith, T. J. (2003). Human rhinovirus capsid dynamics is controlled by canyon flexibility. Virology, 314(1), 34-44.

Rose, N. R. (2009). Myocarditis: infection versus autoimmunity. Journal of Clinical Immunology, 29(6), 730-737.

Saleh, M. C., Van Rij, R. P.\& Andino, R. (2004). RNA silencing in viral infections: insights from poliovirus. Virus Research, 102(1), 11-17.

Sall, A., Liu, Z., Zhang, H. M., Yuan, J., Lim, T., Su, Y.\& Yang, D. (2008). MicroRNAs-based therapeutic strategy for virally induced diseases. Current Drug Discovery Technologies, 5(1), 49-58.

Scherer, L. J.\& Rossi, J. J. (2003). Approaches for the sequence-specific knockdown of mRNA. Nat Biotechnol, 21(12), 1457-1465.

Schubert, S., Grunert, H. P., Zeichhardt, H., Werk, D., Erdmann, V. A.\& Kurreck, J. (2005). Maintaining inhibition: siRNA double expression vectors against coxsackieviral RNAs. Journal of Molecular Biology, 346(2), 457-465.

Schubert, S., Rothe, D., Werk, D., Grunert, H. P., Zeichhardt, H., Erdmann, V. A.\& Kurreck, J. (2007). Strand-specific silencing of a picornavirus by RNA interference: evidence for the superiority of plus-strand specific siRNAs. Antiviral Research, 73(3), 197-205.

Schultz, J. C., Hilliard, A. A., Cooper, L. T., Jr.\& Rihal, C. S. (2009). Diagnosis and treatment of viral myocarditis. Mayo Clinic Proceedings, 84(11), 1001-1009.

Sen, G. L.\& Blau, H. M. (2005). Argonaute 2/RISC resides in sites of mammalian mRNA decay known as cytoplasmic bodies. Nature Cell Biology, 7(6), 633-636.

Shafren, D. R., Williams, D. T.\& Barry, R. D. (1997). A decay-accelerating factor-binding strain of coxsackievirus B3 requires the coxsackievirus-adenovirus receptor protein to mediate lytic infection of rhabdomyosarcoma cells. The Journal of Virology, 71(12), 9844-9848.

Shan, J., Moran-Jones, K., Munro, T. P., Kidd, G. J., Winzor, D. J., Hoek, K. S.\& Smith, R. (2000). Binding of an RNA trafficking response element to heterogeneous nuclear ribonucleoproteins A1 and A2. The Journal of Biological Chemistry, 275(49), 3828638295. 
Si, X., Gao, G., Wong, J., Wang, Y., Zhang, J.\& Luo, H. (2008). Ubiquitination is required for effective replication of coxsackievirus B3. PLoS One, 3(7), e2585.

Si, X., Wang, Y., Wong, J., Zhang, J., McManus, B. M.\& Luo, H. (2007). Dysregulation of the ubiquitin-proteasome system by curcumin suppresses coxsackievirus B3 replication. The Journal of Virology, 81(7), 3142-3150.

Stein, D., Foster, E., Huang, S. B., Weller, D.\& Summerton, J. (1997). A specificity comparison of four antisense types: morpholino, 2'-O-methyl RNA, DNA, and phosphorothioate DNA. Antisense and Nucleic Acid Drug Development, 7(3), 151-157.

Su, H., Joho, S., Huang, Y., Barcena, A., Arakawa-Hoyt, J., Grossman, W.\& Kan, Y. W. (2004). Adeno-associated viral vector delivers cardiac-specific and hypoxia-inducible VEGF expression in ischemic mouse hearts. Proceedings of the National Academy of Sciences U S A, 101(46), 16280-16285.

Tan, E. L., Wong, A. P. Y., Poh, C. L. (2010). Development of potential antiviral stratey against coxswackievirus B4. Virus Research, 150, 85-92.

Tomari, Y.\& Zamore, P. D. (2005). Perspective: machines for RNAi. Genes \& Development, 19(5), 517-529.

Turner, J. J., Fabani, M., Arzumanov, A. A., Ivanova, G.\& Gait, M. J. (2006). Targeting the HIV-1 RNA leader sequence with synthetic oligonucleotides and siRNA: chemistry and cell delivery. Biochimica et Biophysica Acta, 1758(3), 290-300.

van Ooij, M. J., Vogt, D. A., Paul, A., Castro, C., Kuijpers, J., van Kuppeveld, F. J., Cameron, C. E., Wimmer, E., Andino, R.\& Melchers, W. J. (2006). Structural and functional characterization of the coxsackievirus B3 CRE(2C): role of CRE(2C) in negative- and positive-strand RNA synthesis. Journal of General Virology, 87(Pt 1), 103-113.

Verma, B., Bhattacharyya, S.\& Das, S. (2010). Polypyrimidine tract-binding protein interacts with coxsackievirus B3 RNA and influences its translation. Journal of General Virology, 91(Pt 5), 1245-1255.

Walder, R. Y.\& Walder, J. A. (1988). Role of RNase H in hybrid-arrested translation by antisense oligonucleotides. Proceedings of the National Academy of Sciences US A, 85(14), 5011-5015.

Wang, A., Cheung, P. K., Zhang, H., Carthy, C. M., Bohunek, L., Wilson, J. E., McManus, B. M.\& Yang, D. (2001). Specific inhibition of coxsackievirus B3 translation and replication by phosphorothioate antisense oligodeoxynucleotides. Antimicrobial Agents and Chemotherapy, 45(4), 1043-1052.

Wang, J., Bakkers, J. M., Galama, J. M., Bruins Slot, H. J., Pilipenko, E. V., Agol, V. I.\& Melchers, W. J. (1999). Structural requirements of the higher order RNA kissing element in the enteroviral 3'UTR. Nucleic Acids Research, 27(2), 485-490.

Wang, Y. F., Wang, X. Y., Ren, Z., Qian, C. W., Li, Y. C., Kaio, K., Wang, Q. D., Zhang, Y., Zheng, L. Y., Jiang, J. H., Yang, C. R., Liu, Q.\& Zhang, Y. J. (2009). Phyllaemblicin B inhibits Coxsackie virus B3 induced apoptosis and myocarditis. Antiviral Research, 84(2), 150-158.

Werk, D., Pinkert, S., Heim, A., Zeichhardt, H., Grunert, H. P., Poller, W., Erdmann, V. A., Fechner, H.\& Kurreck, J. (2009). Combination of soluble coxsackievirus-adenovirus receptor and anti-coxsackievirus siRNAs exerts synergistic antiviral activity against coxsackievirus B3. Antiviral Res, 83(3), 298-306.

Werk, D., Schubert, S., Lindig, V., Grunert, H. P., Zeichhardt, H., Erdmann, V. A.\& Kurreck, J. (2005). Developing an effective RNA interference strategy against a plus-strand RNA virus: silencing of coxsackievirus B3 and its cognate coxsackievirusadenovirus receptor. Biological Chemistry, 386(9), 857-863. 
Wilson, J. A.\& Richardson, C. D. (2005). Hepatitis C virus replicons escape RNA interference induced by a short interfering RNA directed against the NS5b coding region. The Journal of Virology, 79(11), 7050-7058.

Wong, J., Zhang, J., Si, X., Gao, G., Mao, I., McManus, B. M.\& Luo, H. (2008). Autophagosome supports coxsackievirus B3 replication in host cells. The Journal of Virology, 82(18), 9143-9153.

Wong, L. F., Azzouz, M., Walmsley, L. E., Askham, Z., Wilkes, F. J., Mitrophanous, K. A., Kingsman, S. M.\& Mazarakis, N. D. (2004). Transduction patterns of pseudotyped lentiviral vectors in the nervous system. Molecular Therapy, 9(1), 101-111.

Yajima, T.\& Knowlton, K. U. (2009). Viral myocarditis: from the perspective of the virus. Circulation, 119(19), 2615-2624.

Yanagawa, B., Spiller, O. B., Choy, J., Luo, H., Cheung, P., Zhang, H. M., Goodfellow, I. G., Evans, D. J., Suarez, A., Yang, D.\& McManus, B. M. (2003). Coxsackievirus B3associated myocardial pathology and viral load reduced by recombinant soluble human decay-accelerating factor in mice. Laboratory Investigation, 83(1), 75-85.

Yanagawa, B., Spiller, O. B., Proctor, D. G., Choy, J., Luo, H., Zhang, H. M., Suarez, A., Yang, D.\& McManus, B. M. (2004). Soluble recombinant coxsackievirus and adenovirus receptor abrogates coxsackievirus b3-mediated pancreatitis and myocarditis in mice. Journal of Infectious Diseases, 189(8), 1431-1439.

Yang, D., Wilson, J. E., Anderson, D. R., Bohunek, L., Cordeiro, C., Kandolf, R.\& McManus, B. M. (1997). In vitro mutational and inhibitory analysis of the cis-acting translational elements within the $5^{\prime}$ untranslated region of coxsackievirus B3: potential targets for antiviral action of antisense oligomers. Virology, 228(1), 63-73.

Ye, X., Liu, Z., Hemida, G. M., and Yang, D. C. (2011). Mutation tolerance and targeted delivery of anti-coxsackievirus artificial microRNAs using folate conjugated baterial phage phi29 pRNA. PLoS One, 6(6), e21215.

Ye, X.\& Yang, D. (2009). Recent advances in biological strategies for targeted drug delivery. Cardiovascular and Hematological Disorders - Drug Targets, 9(3), 206-221.

Yuan, J., Cheung, P. K., Zhang, H., Chau, D., Yanagawa, B., Cheung, C., Luo, H., Wang, Y., Suarez, A., McManus, B. M.\& Yang, D. (2004). A phosphorothioate antisense oligodeoxynucleotide specifically inhibits coxsackievirus B3 replication in cardiomyocytes and mouse hearts. Laboratory Investigation, 84(6), 703-714.

Yuan, J., Cheung, P. K., Zhang, H. M., Chau, D.\& Yang, D. (2005). Inhibition of coxsackievirus B3 replication by small interfering RNAs requires perfect sequence match in the central region of the viral positive strand. The Journal of Virology, 79(4), 2151-2159.

Yuan, J., Stein, D. A., Lim, T., Qiu, D., Coughlin, S., Liu, Z., Wang, Y., Blouch, R., Moulton, H. M., Iversen, P. L.\& Yang, D. (2006). Inhibition of coxsackievirus B3 in cell cultures and in mice by peptide-conjugated morpholino oligomers targeting the internal ribosome entry site. The Journal of Virology, 80(23), 11510-11519.

Zhang, H. M., Su, Y., Guo, S., Yuan, J., Lim, T., Liu, J., Guo, P.\& Yang, D. (2009). Targeted delivery of anti-coxsackievirus siRNAs using ligand-conjugated packaging RNAs. Antiviral Research, 83(3), 307-316. 


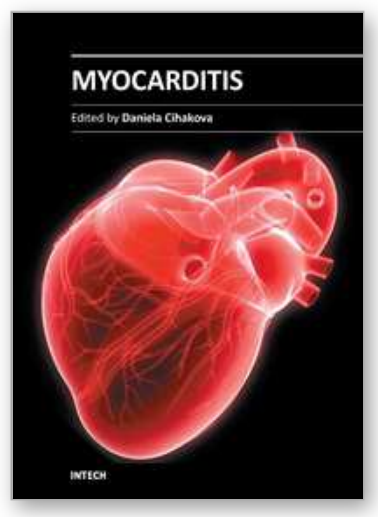

\author{
Myocarditis \\ Edited by Dr. Daniela Cihakova
}

ISBN 978-953-307-289-0

Hard cover, 428 pages

Publisher InTech

Published online 19, October, 2011

Published in print edition October, 2011

Myocarditis, the inflammation of the heart muscle, could be in some cases serious and potentially fatal disease. This book is a comprehensive compilation of studies from leading international experts on various aspects of myocarditis. The first section of the book provides a clinical perspective on the disease. It contains comprehensive reviews of the causes of myocarditis, its classification, diagnosis, and treatment. It also includes reviews of Perimyocarditis; Chagasâ $€^{\mathrm{TM}}$ chronic myocarditis, and myocarditis in HIV-positive patients. The second section of the book focuses on the pathogenesis of myocarditis, discussing pathways and mechanisms activated during viral infection and host immune response during myocarditis. The third, and final, section discusses new findings in the pathogenesis that may lead to new directions for clinical diagnosis, including use of new biomarkers, and new treatments of myocarditis.

\title{
How to reference
}

In order to correctly reference this scholarly work, feel free to copy and paste the following:

Decheng Yang (2011). Nucleic Acid-Based Strategies for the Treatment of Coxsackievirus-Induced Myocarditis, Myocarditis, Dr. Daniela Cihakova (Ed.), ISBN: 978-953-307-289-0, InTech, Available from: http://www.intechopen.com/books/myocarditis/nucleic-acid-based-strategies-for-the-treatment-ofcoxsackievirus-induced-myocarditis

\section{INTECH}

open science | open minds

\author{
InTech Europe \\ University Campus STeP Ri \\ Slavka Krautzeka 83/A \\ 51000 Rijeka, Croatia \\ Phone: +385 (51) 770447 \\ Fax: +385 (51) 686166 \\ www.intechopen.com
}

\author{
InTech China \\ Unit 405, Office Block, Hotel Equatorial Shanghai \\ No.65, Yan An Road (West), Shanghai, 200040, China \\ 中国上海市延安西路65号上海国际贵都大饭店办公楼 405 单元 \\ Phone: +86-21-62489820 \\ Fax: +86-21-62489821
}


(C) 2011 The Author(s). Licensee IntechOpen. This is an open access article distributed under the terms of the Creative Commons Attribution 3.0 License, which permits unrestricted use, distribution, and reproduction in any medium, provided the original work is properly cited. 